\title{
Health IT and Ambulatory Care Quality
}

Carole Roan Gresenz, Scott P. Laughery, Amalia R. Miller and Catherine E. Tucker

RAND Health

RAND Bing Center for Health Economics

RAND Labor \& Population

WR-1 131

August 2016

This paper series made possible by the NIA funded RAND Center for the Study of Aging (P3OAG012815) and the RAND Labor and Population Unit.

RAND working papers are intended to share researchers' latest findings and to solicit informal peer review. They have been approved for circulation by RAND Labor and Population but have not been formally edited or peer reviewed. Unless otherwise indicated, working papers can be quoted and cited without permission of the author, provided the source is clearly referred to as a working paper. RAND's publications do not necessarily reflect the opinions of its research clients and sponsors. RAND尺 is a registered trademark. 
For more information on this publication, visit www.rand.org/pubs/working_papers/WR1131.html

Published by the RAND Corporation, Santa Monica, Calif.

C Copyright 2015 RAND Corporation

RAND $^{\star}$ is a registered trademark

\section{Limited Print and Electronic Distribution Rights}

This document and trademark(s) contained herein are protected by law. This representation of RAND intellectual property is provided for noncommercial use only. Unauthorized posting of this publication online is prohibited. Permission is given to duplicate this document for personal use only, as long as it is unaltered and complete. Permission is required from RAND to reproduce, or reuse in another form, any of its research documents for commercial use. For information on reprint and linking permissions, please visit www.rand.org/pubs/permissions.html.

The RAND Corporation is a research organization that develops solutions to public policy challenges to help make communities throughout the world safer and more secure, healthier and more prosperous. RAND is nonprofit, nonpartisan, and committed to the public interest.

RAND's publications do not necessarily reflect the opinions of its research clients and sponsors.

Support RAND

Make a tax-deductible charitable contribution at

www.rand.org/giving/contribute

www.rand.org 


\title{
Health IT and Ambulatory Care Quality
}

\author{
Carole Roan Gresenz, Scott P. Laughery, Amalia R. Miller and Catherine E. Tucker* \\ August 11, 2016
}

\begin{abstract}
US government investments in health information technology (IT) reflect the significant promise of digitization for improving quality and efficiency in health care. Previous studies of the impact of health IT have focused on the hospital setting, despite the fact that most care is delivered in ambulatory settings. This paper addresses the research omission by studying the effects of healthcare IT on ambulatory care, which we measure using the rate of hospital admissions for conditions identified as sensitive to ambulatory care quality in data drawn from Medicare and the Healthcare Cost and Utilization Project. Results from difference-in-differences models that control for location and time fixed effects, as well as observable factors related to healthcare quality and population demographics, indicate that increased ambulatory IT adoption lowers local area ambulatory care sensitive (ACS) hospitalizations, suggesting quality improvements. The magnitudes imply that a $45 \%$ increase in ambulatory IT adoption in a county (the average increase over our sample period 2003-2012) lowers the ACS admission rate in that county by about $1.6 \%$.
\end{abstract}

*Carole Roan Gresenz is a Senior Economist at the RAND Corporation in Arlington, Virginia. Email: gresenz@rand.org. Scott Laughery is an analyst at the Congressional Budget Office, Washington, DC. Email: scott.laughery@cbo.gov. Amalia Miller is a Professor of Economics, University of Virginia, Charlottesville, VA. Email: armiller@virginia.edu. Catherine Tucker is the Sloan Distinguished Professor of Management, MIT Sloan School of Management, Cambridge, MA. Email: cetucker@mit.edu. We are grateful to the US Agency for Healthcare Research and Quality (AHRQ) and the Bankard Fund for Political Economy at the University of Virginia for financial support, and to Jessica Banthin, Phil Ellis, Leora Friedberg, Mireille Jacobson, Ed Olsen, and Chris Ruhm for helpful comments. The views in this paper are the authors' own and should not be interpreted as those of their employers or sponsors. 


\section{Introduction}

The federal government has devoted considerable resources to promoting the diffusion of information technology (IT) in healthcare. Between January 2011 and April 2015, over 400,000 medical providers received payments totaling over $\$ 30$ billion through the Medicare and Medicaid incentive programs of the 2009 Health Information Technology for Economic and Clinical Health (HITECH) Act. In addition, various provisions of the Patient Protection and Affordable Care Act of 2010 (ACA) are either aimed at increasing the use of health IT or rely on IT investments for their implementation (Clancy et al., 2009). The Office of the National Coordinator for Health Information Technology (ONC) recently awarded more than $\$ 38$ million to improve health information sharing. Underlying these federal investments, and their state-level counterparts, is a belief that creating an electronic rather than a paper interface between patient information and healthcare providers can improve healthcare quality and also save money.

To date, empirical evidence on the effects of health IT on health care quality has been mostly limited to the hospital setting (Agha, 2014; Lee et al., 2013; Lin et al., 2014; Spetz et al., 2014; Freedman et al., 2014; McCullough et al., 2013; Miller and Tucker, 2014b). Although these studies have provided supportive evidence of a positive role for health IT on quality in the hospital inpatient setting, little is known about the impact of IT use on

quality in ambulatory care (Buntin et al., 2011). This is despite the fact that most health services are delivered in such settings and the potential gains from health IT may be larger there.

Theoretically, there are several reasons to believe that adopting digital health records may be important for patients who receive care outside of hospital admissions. These include improved record-keeping and information flow among providers that can be especially important when patients switch providers and care settings for routine and potentially repetitive proecedures (Coleman and Berenson, 2004; Bodenheimer, 2008). Decision support functions 
that increase the standardization of care and patient-centered functions that enable better self-care between visits may also be key for patients receiving care in ambulatory settings. In particular, consumer applications of health IT that aim to enhance the ability of patients (and their caregivers) to share responsibility for actively managing their health (Tang and Newcomb, 1998; Eysenbach, 2000) and following treatment regimens will also depend in part on the local adoption of health IT among area providers. Health IT can also improve communication and information exchange between patients and providers and improve access to medical care and advice.

This paper provides the first empirical evidence on the effects of health IT on ambulatory care quality in the US using national panel data on local area adoption of ambulatory electronic medical records (EMRs). We study the period between 2000 to 2012, that is, years prior to the implementation of HITECH. Our outcome measure is a local area proxy for ambulatory care quality based on rates of hospital admissions for reasons that have been identified by experts as preventable by high quality ambulatory care. We estimate differences-in-differences models that control for location and time fixed effects, as well as observable factors related to healthcare quality and population demographics. Across datasets and models, we find significant reductions in ambulatory care sensitive (ACS) hospitalization rates in an area from increases in ambulatory HIT adoption in the area, suggesting quality improvements. However, these gains are only significant for the population aged 65 and older. Our point estimates suggest possible gains for younger adults, but the findings are not statistically significant. Our results suggest that health IT adoption among ambulatory care providers yields important quality improvements in health care for patients.

This paper has three major contributions.

First, we contribute to the growing literature that attempts to understand in which settings healthcare IT improves health quality outcomes. The theoretical foundation for why healthcare IT may improve the quality of care has been presented in many scholarly and 
popular articles, such as Brailer (2005) and Hillestad et al. (2005). The potential benefits include lower administrative costs, reduced error rates, especially from drug interactions, and reduced rates of duplicate testing, as well as improved patient monitoring. Although the conceptual notion that computers can thereby improve efficiency and improve quality is compelling, countervailing forces exist that may limit or negate the benefits of health IT. The installation of an IT system may prove unsuccessful if providers and other staff resist changing their work patterns, or if they find that the computerization adds to their administrative burdens, introduces inappropriate redundancy to documentation procedures, or is cumbersome to use. There are also concerns about the security and stability of electronic systems, which may limit the willingness of providers to rely on IT solutions. Empirical evidence is therefore essential to determine if health IT is associated with improved quality in the real world, and to measure the magnitude of the gains.

Large national studies have related hospitals' adoption of electronic medical records (EMRs) and other forms of health IT to higher quality care, measured by process improvements and lower mortality. By using panel data that tracks adoption and outcomes over time, researchers have been able to control for differences between early and late adopting hospitals and geographic areas using difference-in-differences approaches (Miller and Tucker, 2011; Agha, 2014; Lee et al., 2013; Lin et al., 2014; Spetz et al., 2014; Freedman et al., 2014; McCullough et al., 2013). This paper extends this literature by showing that there are also positive effects for quality outcomes in ambulatory care centers. Past research on the effects of health IT investment in the ambulatory care setting has primarily consisted of small-scale case studies or surveys, often in single hospitals or large systems (many of which are also early or sophisticated adopters of health IT; see Buntin et al. (2011) and references therein).

Researchers have been constrained in their ability to better assess the impact of ambulatory health IT because of severe data limitations: data sources capturing hospital IT have had limited or no information on ambulatory care, and sources focused on ambulatory health 
IT often have had limited information on the nature or timing of the IT implementation or focus exclusively on very recent years. The importance of using data from many locations, as opposed to data from a single hospital, health system or location, is clear from the conflicting results found in different studies of specific implementations of health IT. This conflict occurred in the hospital setting and may be especially important in the ambulatory setting, where the value of health IT may depend on the specific features and functions of the IT system, as well as the training of providers who use the system and their awareness of its features, and the willingness of staff across the organization to integrate health IT into their usual work-flow (Kaplan et al., 2001). Survey evidence suggests substantial variation across individual physicians and practices in their use and awareness of the various functions of their health IT systems (Hing et al., 2007; Simon et al., 2007; Jha et al., 2006) and points to organizational culture as a factor that supports or inhibits successful health IT deployment.

Second, we contribute to the literature that attempts to understand which patients benefit most from healthcare IT. Work such as Miller and Tucker (2011) and McCullough et al. (2013) has shown that healthcare IT has the greatest benefits for the gravest of cases which benefit the most from the continuity of care. Our research suggests that the largest benefits from healthcare IT in an ambulatory setting are among older patients, who potentially have larger underlying health issues and consequently a more comprehensive medical history to document.

Third, our paper informs public policy by providing new evidence regarding the impact of the HITECH Act on quality of care. Although the original rules exclude ambulatory care centers from receiving direct institutional incentives, the physician incentives indirectly encourage them to adopt the technology. ${ }^{1}$ Our estimates suggest that there are real and measurable benefits from IT in ambulatory facilities in addition to the benefits that have

\footnotetext{
${ }^{1}$ Though it is worth noting that these incentives for 'eligible professionals' (EPs) are muted in the Medicare incentive program because only physicians qualify as EPs. Nurse practitioners and certified nurse midwives also qualify under the Medicaid incentives.
} 
been previously observed in the hospital setting. Indeed, the estimates in our paper suggest that, at least for the older population which could be reached via the established system of targeting Medicare incentives, there are substantial improvements in care quality from the adoption of healthcare IT by ambulatory care centers. Our findings indicate that the costs of the investments made under the HITECH Act need to be weighed against benefits in both the hospital and ambulatory care settings. Our result highlighting the importance of the ambulatory setting is particularly important in the context of current policy initiatives such as Accountable Care Organizations, which attempt to incentivize the provision of care in ambulatory centers rather than high-cost hospitals. ${ }^{2}$

\section{Data}

\subsection{Data on Ambulatory Health IT}

The importance of collecting data over an extended time period relates to the fact that implementations of health IT are not instantaneous, and that there may be a transition period of several years before the full benefits are realized. In order to track how quality of care changes over time as new health IT systems are installed and used, the dataset needs to include several years of observation before installation as well as several years afterward.

We measure local area ambulatory health IT adoption using the 2012 and earlier releases from the Healthcare Information and Management Systems Society (HIMSS) Analytics ${ }^{T M}$ Database (HADB). HIMSS is a non-profit organization "exclusively focused on providing global leadership for the optimal use of information technology (IT) and management systems for the betterment of healthcare" (http://www.himss.org/ASP/index.asp). HIMSS Analytics is the organization that collects, analyzes and disseminates "healthcare data relating to IT processes and environments, products, IS department composition, costs and manage-

\footnotetext{
${ }^{2}$ This desire to promote care in ambulatory settings reflects work such as Jiang et al. (2009), who estimate that in 2006 alone, over four million hospital admissions could have been prevented, with a cost savings of over $\$ 30$ billion, through effective ambulatory care and adequate patient self-management.
} 
ment metrics, healthcare trends and purchasing decisions" (http://www.himssanalytics.org). The HADB is derived from the Dorenfest IHDS+ Database and released annually starting in 2005. From 1998 to 2004, data are available from the Dorenfest Complete IHDS+ Database, and from 1986 to 1995, there is a more limited Dorenfest 3000+ Database.

The HADB has several advantages as a data source for this research. It includes a large set of ambulatory providers from across the country and the availability of information over time allows us to construct the multi-year panel crucial for our difference-in-differences approach. The current version of the database includes data on over 20,000 ambulatory providers nationwide. (While we also have access to earlier versions of the database, those were more focused on hospitals and contained less data on ambulatory providers.) The HADB contains detailed data for several health IT applications, with information about the functions, vendor, implementation status and contract date. The HADB is considered an authoritative source for tracking hospital IT adoption and has previously been used in research on hospital health IT adoption, such as Miller and Tucker (2009), Jones et al. (2010), and Angst et al. (2010). Moreover, The HADB contains detailed data for several health IT applications, with information about the functions, vendor, implementation status and contract date.

Surveys of the status of ambulatory health IT adoption frequently rely on the HADB (see, for example, the recent 2011 report on the "State of Health Information Technology in California" by the California HealthCare Foundation). Other potential data sources for ambulatory health IT are limited in key ways. Some are one-shot surveys of relatively small numbers of providers that cannot be used to generate reliable measures of local adoption or to compute changes in adoption over time. Examples include the National Association of Community Health Centers' 2008 HIT Survey of Health Centers (which had a 37\% response rate); the Center for Studying Health System Change 2008 Health Tracking Physician Survey of over 4,700 physicians (62\% response rate), and the Harris Interactive 2009 survey of 1,442 
primary care physicians and pediatricians (39\% response rate). These samples are generally far smaller than the HADB and would be less reliable for computing local information, even at a single point in time. ${ }^{3}$

HADB defines an entity as ambulatory if it offers preventive, diagnostic, therapeutic and rehabilitative services to individuals not classified as inpatients or residents. This includes physician offices and clinics.

Ambulatory care entities are included in the HADB if they are affiliated with a larger health care delivery system, either because they are owned (in whole or in part), leased, or managed by the system. The definition of a system is rather broad in the data, and includes some with only a single hospital. Nevertheless, this selection rule means that our measure of health IT adoption is not available for the full universe of ambulatory providers. It does not capture health IT adoption among free-standing physician offices or ambulatory care providers who are not affiliated with any healthcare system. While the exclusion of such ambulatory providers may limit the generalizability of the results (and may bias us against finding statistically significant effects), no panel data sources exist that provide information on health IT use for the entire set of all ambulatory providers in the United States.

One possible advantage of the HADB inclusion criteria is that they focus our analyses on the set of ambulatory care providers most likely to exchange patient information and benefit from health IT adoption. Miller and Tucker (2014a) report evidence from the AHA special survey of hospitals regarding health IT and information exchange. A key finding of that paper was that hospitals that are part of larger systems are more likely to exchange patient information electronically with other providers (hospitals and ambulatory care providers), but they are less likely to exchange information outside of their systems. This implies that health IT adoption may be most useful for providers who are able to exchange data with

\footnotetext{
${ }^{3}$ In contrast, the SK\&A marketing survey contains a larger set of ambulatory providers than the HADB, but their data are too recent for our purposes. The question on EMR adoption only started in 2008, and information on specific types of software and functionalities started even more recently.
} 
Table 1: Ambulatory HIT Diffusion over the 2003-2012 Sample Period

\begin{tabular}{ccc}
\hline \hline & & \\
& Mean & Std. Dev. \\
\hline 2003 & 0.22 & 0.38 \\
2004 & 0.26 & 0.39 \\
2005 & 0.31 & 0.42 \\
2006 & 0.39 & 0.44 \\
2007 & 0.42 & 0.45 \\
2008 & 0.44 & 0.44 \\
2009 & 0.50 & 0.43 \\
2010 & 0.57 & 0.43 \\
2011 & 0.64 & 0.41 \\
2012 & 0.68 & 0.39 \\
Total & 0.44 & 0.44 \\
\hline \hline
\end{tabular}

County-level averages of facility-level adoption data, weighted by size (physicians).

other providers through a shared system. One reason for this may be concerns about privacy and security of private patient health information.

Our outcome measure (see Section 2.2) is the ambulatory care sensitive hospitalization rate in a local geographic area (county). Thus, health IT adoption should ideally be measured for providers who serve the patient population in the area. We create a county-level measure of health IT adoption among ambulatory providers as our primary measure, where the county level measure is based on the physical location of providers. While a health IT adoption measure constructed for a larger geographic area may be more likely to include all of the relevant providers serving the patients using inpatient hospital care in that county (who are included in the outcome measure), such a measure would also provide a less precise measure of local health IT for individuals who seek care within county boundaries as well as show less variation at any point in time. ${ }^{4}$

Our measure of ambulatory health IT is whether an ambulatory EMR system is in place. This is the backbone system that stores and manages digital patient records for an ambu-

\footnotetext{
${ }^{4}$ We aggregate adoption variables across facilities to the county level wighting by practice size (number of physicians). We use AHRQ's modified county definition that groups together cities and counties in Virginia.
} 
latory provider. We use information from contract dates to identify the timing of adoption in order to construct a panel dataset. One limitation is that we assume that contract dates recorded in our data reflect an entity's first (and not just most recent) adoption decision. The data also include information on decisions to replace existing systems. Empirically, we find it is rare for such decisions installed within the past decade, which suggests that our assumption about contract dates indicating first adoption is likely to be valid in most cases.

Table 1 shows the average county-level adoption rate of ambulatory EMR (weighted by facility size within each county) is steadily increasing in each year of our data. The rate for 2008 in our sample is 0.44 . This is substantially higher than the overall rate of $17 \%$ found in the DesRoches et al. (2008) survey of physicians, but comparable to the rate of $51 \%$ in that paper for physicians in larger groups. Over the sample period, average EMR rates increased by 0.46 , which is about the level of increase at the median county in the sample $(0.47){ }^{5}$

\subsection{Data on Quality: Prevention Indicators}

We use an indirect measure of ambulatory care quality based on hospital admissions for ambulatory care sensitive (ACS) conditions. ACS conditions are those for which appropriate ambulatory care can prevent or reduce hospitalization. For example, good management of asthma at the first sign of exacerbation can usually alleviate symptoms or keep them from progressing to the point that hospitalization is required. Other examples of ACS conditions include dehydration and hypertension. Hospitalizations for ACS conditions are interpreted as indicating problems in access to ambulatory care or poor-quality outpatient management (Billings et al., 2000). Despite the fact that ACS hospitalizations reflect hospital data, they provide insight into the health care system outside the hospital setting (AHRQ, 2007). Indeed, ACS hospitalizations were included in a set of metrics identified by Kern et al. (2009)

\footnotetext{
${ }^{5}$ Interestingly, the main results in Table 3 are not driven by counties with unusually large increases in EMR adoption. In fact, when we split the sample into counties with above and below median rates of change in ambulatory EMR over the period, we find statistically and economicaly significant benefits for both groups.
} 
that were deemed most appropriate for capturing the potential quality effects of ambulatory health IT. More broadly, ACS hospitalizations were one of a set of 20 indicators chosen by the Institute of Medicine (IOM) as critical for understanding and tracking the state of the nation's health system and one of only three key measures the committee pointed to for monitoring the effectiveness of care (IOM, 2009).

Standard, well-validated methods exist for classifying ACS hospitalizations. These methods, which were first established by Billings et al. (2000) and then developed by AHRQ into "Prevention Quality Indicators" (PQIs), are used by AHRQ and several states in monitoring the progress of their health care system. We constructed county-level PQI measures using the AHRQ algorithms (version 5.0) applied to hospitalization records from the Medicare Inpatient Limited Data Set (LDS). The Inpatient LDS data include diagnosis and procedure codes along with patient age, sex, and county of residence corresponding to every hospitalization of a Medicare fee-for-service beneficiary between 2003 and 2012 (approximately 13 million records per year). ${ }^{6}$

\subsection{Data on Controls}

Control variables include demographic and socioeconomic characteristics of local areas as well as healthcare factors that are likely to affect the ACS rate and that may change differently over time across different areas. We use multiple data sources to construct control variables, including the US Census Bureau County Intercensal Estimates (for county-level population); the Health Resources and Services Administration's Area Health Resource File (AHRF), for primary care physician supply, supply of hospital beds, and number of federally-qualified health center grantees in the county (US Department of Health and Human Services, Health Resources and Services Administration, Bureau of Health Workforce, 2014); the US Census

\footnotetext{
${ }^{6}$ To address the high rate of missing county data in the 2008 LDS file (86\%), we use unique patient identifiers to match individual records from other years and impute location. This lowers the rate of missing geographic information to $18 \%$, which is still somewhat high, but more in line with rates of missing data for other years. Since rates of missing data are unlikely to be related to EMR adoption in 2008, this is unlikely to bias our estimates of its impact.
} 
Table 2: Summary Statistics: Control Variables and Medicare Population Outcomes

\begin{tabular}{lccccc}
\hline \hline & & & & & \\
& Mean & Std. Dev. & Min. & Max. & Obs. \\
\hline PQI Count & 713.1 & 1638.4 & 0 & 46126 & 25030 \\
PQI Rate & 6300.0 & 2937.6 & 0 & 29645.4 & 25030 \\
Acute PQI Rate (per 100,000) & 2929.0 & 1459.6 & 0 & 17180.6 & 25030 \\
Chronic PQI Rate (per 100,000) & 3372.8 & 1673.6 & 0 & 18453.6 & 25030 \\
Population Age 65+ (00,000s) & 0.15 & 0.39 & 0.0013 & 11.4 & 25030 \\
Short-Term Hosp. Beds (Per 1,000) & 3.21 & 3.89 & 0 & 53.2 & 25030 \\
Primary Care Physicians (Per 10,000) & 6.91 & 4.38 & 0 & 94.5 & 25030 \\
FQHC Grantees (per 100,000 Low Income) & 14.0 & 34.3 & 0 & 488.6 & 25030 \\
Govt Health \& Hosp. Spending (000,000s USD) & 5100.9 & 5268.1 & 95 & 33773.7 & 25030 \\
State HMO Penetration Rate & 15.8 & 9.69 & 0 & 65.5 & 25030 \\
State Uninsured Percent & 14.5 & 4.15 & 3.36 & 25.5 & 25030 \\
Median Household Income (000s USD) & 42.5 & 10.9 & 17.8 & 119.5 & 25030 \\
County Poverty Percent & 14.5 & 5.42 & 2.39 & 47.8 & 25030 \\
\hline \hline
\end{tabular}

County-year unit of observation. PQI count is the number of ACS hospital admissions among adults insured by Medicare. The PQI rate is the ACS hospitalization count per 100,000 population aged 65 and over in the county. Acute and chronic PQI rates are defined similarly and reflect ACS hospitalizations for acute vs. chronic conditions. Hospital beds and primary care physicians are scaled to total population in the county. Federally qualified health centers (FQHCs) are organizations receiving grants under Section 330 of the Public Health Service Act (PHS). FQHCs are scaled to low-income population in the county. 
Bureau Small Area Income and Poverty Estimates database, for poverty rates and median household income; Kaiser Family Foundation State Health Facts, for percent uninsured and HMO penetration rate (online at http://kff.org/statedata; based on the data from the Census Bureau's March Supplement to the Current Population Survey and HealthLeaders InterStudy); and the Census of Governments/Annual Survey of State and Local Government, Finances for state and local government health and hospital spending.

We control for health care market and demographic characteristics of the population that are likely to influence the county ACS hospitalization rate, including the supply of primary care, scope of the local health care safety net, availability of hospital beds, pervasiveness of managed care, and insurance status and income level of the population. A larger supply of primary care providers, richer safety-net, and greater managed care presence are likely to reduce ACS hospitalizations, while greater hospital bed availability, higher rates of uninsurance and lower population income levels are likely to be associated with higher ACS rates.

We measure primary care physician supply using the county-level number (per 10,000 population) of non-federal doctors of medicine (M.D.) and doctors of osteopathy (D.O.) providing direct patient care who practice principally in general internal medicine, general or family practice, pediatrics or obstetrics and gynecology. Our hospital supply measure includes the number short-term general hospital beds per 1,000 in the county. Our safetynet measures include the number of federally qualified health center (FQHCs) grantees per 100,000 low income population in the county and a state-level health and hospital spending variable, which includes state, county, and local expenditures for public health administration, immunization programs, outpatient health clinics, hospital facilities directly administered by the government, and other support for the provision of hospital care (Gresenz et al., 2007). The HMO penetration rate is the percent of the total population in the state enrolled in an HMO and the uninsured rate is the percentage of the total population in the state without health insurance coverage during the year. The county level poverty rate indicates 
the percentage of the population in the county with income less than the federal poverty line (FPL).

Table 2 reports summary statistics on the control variables for our primary sample of 25,030 county-year observations for which we have information on ambulatory EMR adoption and PQIs. This does not include the full set of counties in the US; rather, counties are omitted if there are no data on ambulatory providers in the county in the HADB. Counties in our sample tend to have more hospital beds and primary care physicians per population and more FQHC grantees per low-income population than excluded counties. They also have higher median household income and lower poverty percents. They are in states with higher levels of health spending and HMO penetration, and lower uninsured percentages.

\section{Empirical Analysis and Results}

We use our panel data to estimate difference-in-differences models in order to understand the impact of health IT on ambulatory care quality. We include fixed effects for location and time. This is similar to the approach used in the literature on hospital IT adoption. One difference is that our quality measure is not linked to specific ambulatory care facilities, but is based on the local area. This is similar to Miller and Tucker (2011), who study hospital IT and infant health. That paper also uses hospital privacy laws as a source of exogenous variation in EMR adoption and confirms the qualitative findings from the basic fixed effects models. We are not able to use those instruments in this paper because of the different setting and time period, but the lack of significant bias in the OLS models in Miller and Tucker (2011), as well as other robustness and falsification checks in the hospital context found in the literature, all provide support for the fixed effect approach in this paper in the ambulatory setting. 


\subsection{Main Results for the Medicare Population}

Column 1 of Table 3 reports results from regressions that control only for the ambulatory EMR adoption rate, county and year fixed effects, and county population. Standard errors are clustered at the county level to account for serial correlation within counties. The estimate indicates that a 45 percentage point increase in ambulatory EMR adoption in a county (the average increase over our sample period) is associated with a 104 point drop in PQI admission rate (per 100,000 relevant population per year) in that county, or about a $1.6 \%$ decline.

Adding controls has a limited effect on our estimate of the effect of health IT on the PQI rate (Column 2), although several controls have statistically significant effects on the PQI rate. ACS admissions are higher when there are more hospital beds per capita, which may reflect availability or demand for hospital care. The negative coefficient for the state percent uninsured variable suggests a positive association between the availability of health insurance and hospital admissions overall as well as hospital emergency visits (Card et al., 2008; Finkelstein et al., 2012). Higher median income level in a county and a higher county-level poverty rate are both associated with higher ACS hospitalization rates. Finally, increasing HMO penetration is associated with a lower ACS admission rate.

The last two columns of Table 3 show robustness checks for alternative estimation models. In Column 3, we add state-specific linear time trends to account for the possibility that states with greater ambulatory EMR adoption during the time period happened to be those with decreasing trends in ACS rates. ${ }^{7}$ In Column 4, we report estimates from an unweighted version of the model. Both specifications show a reduction in ACS rates from an increase in EMR adoption, though the coefficient estimates are smaller in magnitude.

Table 4 considers alternative outcome measures. Column 1 uses the ambulatory care

\footnotetext{
${ }^{7}$ Including state-specific linear trends also leaves the finding of negative and significant effects of ambulatory EMR unchanged in the robustness checks considering alternative outcome measures and with the sample restrictions reported in Tables 4 and 5, respectively.
} 
Table 3: Main Results

\begin{tabular}{lcccc}
\hline \hline & $(1)$ & $(2)$ & $(3)$ & $(4)$ \\
& PQI Rate & PQI Rate & PQI Rate & PQI Rate \\
& b/se & b/se & b/se & b/se \\
\hline Ambulatory EMR & $-231.3^{* * *}$ & $-245.1^{* * *}$ & $-175.6^{* * *}$ & $-118.4^{* * *}$ \\
& $(61.6)$ & $(54.8)$ & $(38.4)$ & $(41.9)$ \\
Population Age 65+ (00,000s) & $637.3^{* * *}$ & 414.4 & $304.6^{* * *}$ & $3838.3^{* * *}$ \\
& $(233.0)$ & $(302.2)$ & $(111.5)$ & $(802.8)$ \\
Short-Term Hosp. Beds (Per 1,000) & & $64.1^{* *}$ & $36.7^{* *}$ & 31.7 \\
& & $(26.9)$ & $(18.3)$ & $(20.3)$ \\
Primary Care Physicians (Per 10,000) & & 22.9 & $64.9^{* * *}$ & $51.7^{* * *}$ \\
& & $(19.7)$ & $(17.5)$ & $(13.6)$ \\
FQHC Grantees (per 100,000 Low Income) & & -2.21 & $-2.51^{*}$ & -0.54 \\
& & $(1.82)$ & $(1.35)$ & $(1.38)$ \\
Govt Health \& Hosp. Spending (000,000s USD) & & 0.019 & $-0.10^{* * *}$ & 0.017 \\
Median Household Income (000s USD) & & $(0.017)$ & $(0.030)$ & $(0.015)$ \\
County Poverty Percent & & $84.5^{* * *}$ & $46.9^{* * *}$ & $49.4^{* * *}$ \\
County Fixed Effects & & $(7.87)$ & $(5.14)$ & $(5.34)$ \\
Year Fixed Effects & & $29.8^{* * *}$ & $15.2^{*}$ & $13.4^{*}$ \\
Observations & & $(10.3)$ & $(8.10)$ & $(7.19)$ \\
Counties & & Yes & Yes & Yes \\
\hline \hline
\end{tabular}

Weighted least squares with county population weights in Columns (1) to (3); unweighted least squares in Column (4). Column (3) includes state-specific linear time trends. Robust standard errors clustered at the county level. ${ }^{*} p<0.10$, ** $p<0.05,{ }^{* * *} p<0.01$ 
Table 4: Alternative Outcome Measures

\begin{tabular}{lcccc}
\hline \hline & $(1)$ & $(2)$ & $(3)$ & $(4)$ \\
& Acute PQI Rate & Chronic PQI Rate & PQI Count & Log PQI Rate \\
& b/se & b/se & b/se & b/se \\
\hline Ambulatory EMR & $-93.7^{* * *}$ & $-151.4^{* * *}$ & $-196.7^{* *}$ & $-0.049^{* * *}$ \\
& $(24.9)$ & $(32.3)$ & $(80.9)$ & $(0.017)$ \\
Controls & Yes & Yes & Yes & Yes \\
County Fixed Effects & Yes & Yes & Yes & Yes \\
Year Fixed Effects & Yes & Yes & Yes & Yes \\
\hline Observations & 25030 & 25030 & 25030 & 25029 \\
Counties & 2503 & 2503 & 2503 & 2503 \\
\hline \hline
\end{tabular}

Weighted least squares with county population weights. Robust standard errors clustered at the county level. All models include the full set of controls from Column (2) of Table 3. * $p<0.10,{ }^{* *} p<0.05,{ }^{* * *} p<0.01$

sensitive hospitalization rate for acute health conditions and Column 2 uses the rate for chronic conditions. Columns 1 and 2 show that the overall decline in ACS rates comes from declines in hospitalization rates related to acute conditions, such as urinary tract infections, and chronic conditions, such as hypertension and diabetes. The absolute magnitude of the decline in hospitalizations for chronic conditions is larger, but the effects are more similar in proportion to their average values.

The remaining columns apply different transformations to the dependent variable. In Column 3 we use the count of ACS hospitalizations (instead of the rate). Because the population over age 65 in a county is an imperfect measure of the number of Medicare feefor-service beneficiaries, the ACS rate is potentially subject to measurement error. The ACS count, by contrast, is not. In Column 4, we take the natural logarithm of the ACS rate. Our estimates are robust to using ACS counts instead of rates and when taking the natural logarithm of the PQI rate.

In a final robustness check, we repeat the main regressions using subsamples of our analytic data set that are limited to counties for which we have more complete coverage of physicians providing ambulatory care in the HADB. We calculate the coverage of the 
Table 5: Limiting the Sample to Counties with High Ambulatory EMR Data Coverage

\begin{tabular}{lcccc}
\hline \hline & $(1)$ & $(2)$ & $(3)$ & $(4)$ \\
& All Counties & $>10 \%$ of Docs & $>25 \%$ of Docs & $>50 \%$ of Docs \\
& $\mathrm{b} / \mathrm{se}$ & $\mathrm{b} / \mathrm{se}$ & $\mathrm{b} / \mathrm{se}$ & $\mathrm{b} / \mathrm{se}$ \\
\hline Ambulatory EMR & $-245.1^{* * *}$ & $-298.8^{* * *}$ & $-216.7^{* * *}$ & $-128.7^{* *}$ \\
& $(54.8)$ & $(55.0)$ & $(60.2)$ & $(60.8)$ \\
Controls & Yes & Yes & Yes & Yes \\
County Fixed Effects & Yes & Yes & Yes & Yes \\
Year Fixed Effects & Yes & Yes & Yes & Yes \\
\hline Observations & 25030 & 22141 & 18187 & 12554 \\
Counties & 2503 & 2252 & 1925 & 1431 \\
\hline \hline
\end{tabular}

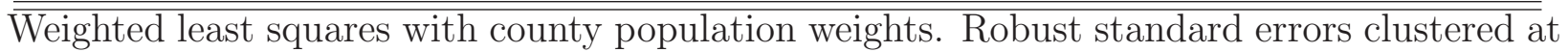
the county level. All models include the full set of controls from Column (2) of Table 3. * $p<0.10,{ }^{* *} p<0.05,{ }^{* * *} p<0.01$

HADB data on ambulatory care providers by comparing the physician count in the HADB to the count of primary care physicians in the county during 2012 from the AHRF data. The comparison is imperfect because, for example, the HADB measure is not restricted to primary care physicians, so we should not expect a perfect match. Nevertheless, we should have more confidence in the relevance of our measure of ambulatory EMR adoption in counties with higher ratios of HADB to AHRF data. The first column of Table 5 shows the main estimate from Table 3 (Column 2 of that table) for the full sample of roughly 2500 counties. Column 2 limits the sample to counties with a ratio of HADB to AHRF physicians greater than 10\% (approximately 2200 counties; Column 3 includes counties for which the estimated HADB coverage is $25 \%$ or greater ( 1900 counties) and Column 4 requires an estimated HADB coverage rate of $50 \%$ or greater (approximately 1430 counties, or roughly half of the full sample of counties).

The main result is robust to the smaller samples of counties, although the magnitude changes. The effect size is smaller in analyses that use only counties for which estimated HADB coverage is over 20 or 50 percent. These results suggest that a 45 percentage point increase in ambulatory EMR adoption in a county (the average increase over our sample 
period) is associated with a 58 point drop in the ACS rate (per 100,000 relevant population per year) in that county, or about a $0.9 \%$ decline.

\subsection{Results from Other Demographic Groups}

A natural question to ask is if the benefits associated with ambulatory EMR adoption for the Medicare aged population are also present for younger age groups.

We address the question using inpatient discharge data from the Nationwide Inpatient Sample (NIS), which is part of the Healthcare Cost and Utilization Project (HCUP). Our NIS data span 2000-2010. Unlike the Medicare data, the NIS is based on a sample of hospitals in participating states $(A H R Q, 2010) .{ }^{8}$ The number of participating states has risen over time from 8 in 1988 to 28 in 2000 and 44 in 2010. The major disadvantage of these data is that the set of hospitals is not stable over time, so the county-year database is a repeated crosssection rather than a true panel, and there may be random noise in the outcome variable that is related to changes in the sample. This variation may make it harder for us to detect effects of ambulatory EMR on outcomes (and is the reason that we focus on the Medicare data for our main analyses.)

Nevertheless, with roughly 8 million hospital stays each year, the NIS is the largest inpatient care database in the United States. It also has the major advantage, especially relative to the Medicare data, that it includes discharge information for patients regardless of payment sources, including private insurance, public insurance, and self-pay. We can therefore use the NIS data as an alternative source to measure the effects for the over 65 population and also to compare that population to other age groups in the general population.

\footnotetext{
${ }^{8}$ Beginning with the 2012 release, the NIS has been redesigned and now samples hospital discharges rather than hospitals. The redesigned sample does not include county identifiers and therefore cannot be used for our analysis.
} 
Table 6: Differential Effects by Age

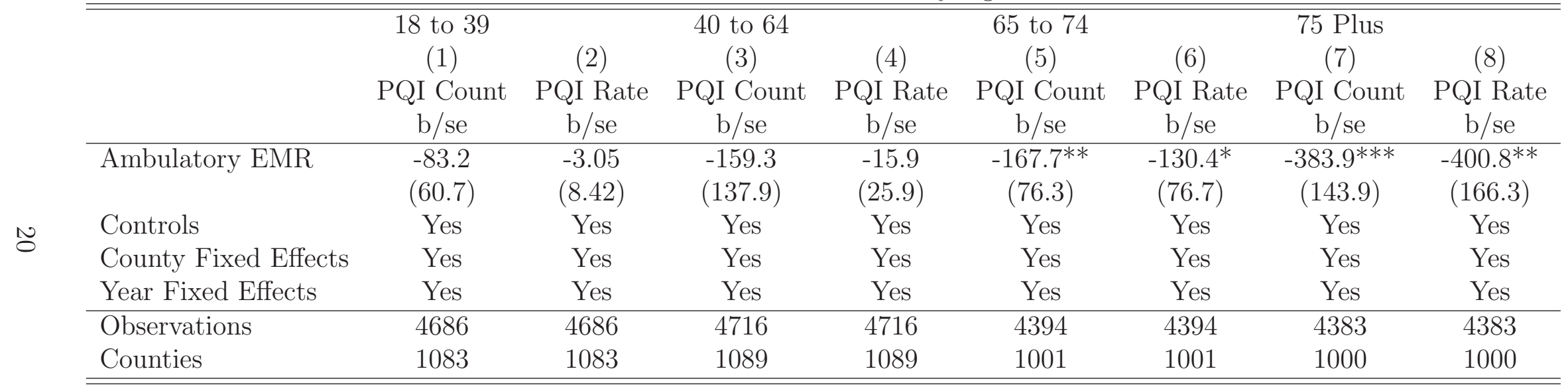

Weighted least squares with county population weights. Robust standard errors clustered at the county level. All models include the full set of controls from Column (2) of Table $3 .{ }^{*} p<0.10,{ }^{* *} p<0.05,{ }^{* * *} p<0.01$ Sample restricted to county-years with at least 1,000 population in the demographic subgroup. Summary statistics on PQI Rates by subgroup are reported in Table A-2. 
Table 6 reports estimates using NIS data on 4 age groups: 18 to 39, 40 to 64, 65 to 74 and 75 and older. The regression models, as above, are weighted by county population and include controls for changing county and state characteristics as well as year and county fixed effects. Robust standard errors are clustered at the county level and outcomes are reported for both PQI counts and rates (per 100,000 population). The sample sizes are substantially smaller for the NIS analysis compared to the Medicare analysis in the previous section because of limited coverage of counties in the NIS.

Across the columns of the table, the estimated coefficient for ambulatory EMR coverage is negative and increasing in magnitude for older ages. This indicates that, while there may be benefits from ambulatory EMR for younger patients, the largest gains accrue to older ones. Although older groups have higher baseline PQI rates, as shown in Table A-2, the effect increases in magnitude both in absolute terms and relative to baseline rates. The estimate in Column 2 of Table 6 is equal to 1 percent of the mean PQI rate for 18 to 39-year-old patients, whereas the estimate in Column 8 is equal to 7 percent of the mean PQI rate for patients over 75 .

Table 7 shows estimated effects of ambulatory EMRs on quality of pediatric care. Because the PQI measures apply only to the adult population, this analysis uses the subset of AHRQ's "Pediatric Quality Indicators" (PDIs) related to preventable hospitalizations (e.g., asthma, diabetes, gastroenteritis, perforated appendix and urinary tract infection admission rates) for children aged 6 to 17 . We constructed PDI counts using the NIS and another HCUP database: the Kids' Inpatient Database (KID). The KID is a sample of pediatric discharges defined as discharges where the patient was age 20 or younger at admission - from community, non-rehabilitation hospitals in states participating in HCUP (AHRQ, 2008). Like the NIS, the number of states participating has risen over time (from 22 to 44 from 1997 to 2009 for the KID); the KID includes discharges for all payers; and data include patient characteristics, hospital characteristics and clinical information (diagnoses, procedures) associated with the 
Table 7: Ambulatory EMR and Pediatric Care

\begin{tabular}{lcccc}
\hline \hline & NIS & & KID & \\
& $(1)$ & $(2)$ & $(3)$ & $(4)$ \\
& PDI Count & PDI Rate & PDI Count & PDI Rate \\
& $\mathrm{b} / \mathrm{se}$ & $\mathrm{b} / \mathrm{se}$ & $\mathrm{b} / \mathrm{se}$ & $\mathrm{b} / \mathrm{se}$ \\
\hline Ambulatory EMR & -55.1 & -8.22 & -50.8 & 3.37 \\
& $(42.2)$ & $(6.67)$ & $(39.1)$ & $(5.63)$ \\
Local Controls & Yes & Yes & Yes & Yes \\
County Fixed Effects & Yes & Yes & Yes & Yes \\
Year Fixed Effects & Yes & Yes & Yes & Yes \\
\hline Observations & 4622 & 4622 & 3552 & 3552 \\
Counties & 1084 & 1084 & 1058 & 1058 \\
\hline \hline
\end{tabular}

PDI count is the number of hospital admissions identified as part of the prevention subcategory of "Pediatric Quality Indicators" by AHRQ. Pediatric admissions data are from the Nationwide Inpatient Sample (NIS) or the Kids' Inpatient Database (KID). Weighted least squares with county population weights. Robust standard errors clustered at the county level. All models include the full set of controls from Column (2) of Table 3. ${ }^{*} p<0.10$, ** $p<0.05,{ }^{* * *} p<0.01$

inpatient stay. Unlike the NIS, which is available in every year, the KID is available every three years beginning with 1997. Our KID sample uses data from 2000, 2003, 2006, and 2009.

The estimated effects on PDIs are inconsistent in sign across the models and samples and not statistically significant. This lack of an effect for children may be caused by limitations in the samples and available measures (e.g., our IT adoption measures are not specific to pediatric care) or it may reflect the fact that ambulatory EMRs are more important for quality for adults, and especially older adults, rather than children.

\section{Implications}

As the Office of the National Coordinator for Health Information Technology (ONC) describes it, "The nation has embarked upon an unprecedented effort to transform the flow of information in health care in order to improve the quality and efficiency of care." The goals of federal health IT investments are broad, including increasing the adoption of health IT, 
improving health care quality and access, supporting the delivery of high value care, and improving clinical and community services and population health (ONC, 2015). Reflecting the focus of policy incentives such as the institutional incentives for hospitals in the HITECH Act (that are not available to ambulatory care centers), empirical research on the effects of health IT adoption on quality of care has been focused on the hospital setting. This is despite the fact that improving quality at ambulatory facilities may help lower costs of routine healthcare relative by preventing hospitalizations.

The goal of this paper is to expand the scope of empirical evidence on health IT adoption by specifically analyzing the effects of health IT on ambulatory care quality in the US. We do so using a measure of quality derived from hospitalizations - the ACS rate - but which provides information on the quality of ambulatory care. We find significant reductions in ACS rates in an area following increased ambulatory HIT adoption in the area, suggesting quality improvements among older (65 and over) populations. This holds true across a range of specifications, including for sensitivity analyses that vary the sample of counties and outcome measure used in analysis. Results for other age groups are not statistically significant but our point estimates for children, young adults (18-39), and those 40-64 suggest an inverse relationship between health IT adoption and ACS rates; however, the standard errors of the estimates are relatively large and thus the estimates lack statistical significance. Taken as a whole, our results suggest that health IT adoption yields improvements in quality, especially for the kind of older adults most likely to be affected by organizational incentives based on Medicare intake.

There are of course limitations to our study. First, our results are imprecise for younger populations and more research is needed to explore whether the benefits for younger populations (less than age 65) may be heterogeneous, and specifically be more pronounced for potentially vulnerable groups of patients such as the uninsured, publicly insured, low income or chronically ill. Second, we focus on basic EHR records and further research is also needed 
to explore how specific health IT components (e.g. practice management software, or PACS) may contribute to quality improvements in ambulatory care. Third, our findings focus on the subset of ambulatory providers who are affiliated with a larger health system, including by being owned, leased or managed by the system. Therefore, our findings provide an estimate of the effects of health IT on ambulatory care quality for ambulatory providers who may be more likely than others to be exchanging information with hospitals and other providers in their system because of the nexus of affiliation. It is possible that there may be smaller effects if ambulatory providers are less well placed to share information. ONC has recently focused on interoperability of health IT and information sharing, given the possibility that the benefits of health IT may grow exponentially through the added dimension of exchange, but this is not something we are able to study explicitly. Notwithstanding these limitations, our paper represents a useful first step in calibrating the benefits of electronic medical records for an area of practice which has not hitherto been the focus of attention. 


\section{References}

Agency for Healthcare Research and Quality (AHRQ) (2001, October). Guide to Prevention Quality Indicators (3.1 ed.). Rockville, MD.

Agency for Healthcare Research and Quality (AHRQ) (2008). Introduction to the HCUP Kids' Inpatient Database (KID), 2006. Rockville, MD.

Agency for Healthcare Research and Quality (AHRQ) (2010). Introduction to the HCUP Nationwide Inpatient Sample (NIS), 2008. Rockville, MD.

Agha, L. (2014). The effects of health information technology on the costs and quality of medical care. Journal of Health Economics 34, 19 - 30.

Angst, C. M., R. Agarwal, V. Sambamurthy, and K. Kelley (2010). Social contagion and information technology diffusion: the adoption of electronic medical records in us hospitals. Management Science 56(8), 1219-1241.

Billings, J., N. Parikh, and T. Mijanovich (2000, November). Emergency department use in new york city: a substitute for primary care? Issue brief (Commonwealth Fund) (433), $1-5$.

Bodenheimer, T. (2008). Coordinating care - a perilous journey through the health care system. New England Journal of Medicine 358(10), 1064-1071.

Brailer, D. J. (2005). Interoperability: The Key To The Future Health Care System. Health Affairs, w5.19-21.

Buntin, M. B., M. F. Burke, M. C. Hoaglin, and D. Blumenthal (2011). The benefits of health information technology: a review of the recent literature shows predominantly positive results. Health Affairs 30(3), 464-471. 
Card, D., C. Dobkin, and N. Maestas (2008). The impact of nearly universal insurance coverage on health care utilization: Evidence from medicare. The American Economic Review, 2242-2258.

Clancy, C. M., K. M. Anderson, and P. J. White (2009). Investing in health information infrastructure: can it help achieve health reform? Health Affairs 28(2), 478-482.

Coleman, E. A. and R. A. Berenson (2004). Lost in transition: challenges and opportunities for improving the quality of transitional care. Annals of Internal Medicine 141(7), 533536.

DesRoches, C. M., E. G. Campbell, S. R. Rao, K. Donelan, T. G. Ferris, A. Jha, R. Kaushal, D. E. Levy, S. Rosenbaum, A. E. Shields, and D. Blumenthal (2008). Electronic Health Records in Ambulatory Care: A National Survey of Physicians. New England Journal of Medicine 359(1), 50-60.

Eysenbach, G. (2000). Recent advances: Consumer health informatics. BMJ 320, 1713-1716.

Finkelstein, A., S. Taubman, B. Wright, M. Bernstein, J. Gruber, J. P. Newhouse, H. Allen, K. Baicker, et al. (2012). The oregon health insurance experiment: Evidence from the first year. The Quarterly Journal of Economics 127(3), 1057-1106.

Freedman, S., H. Lin, and J. Prince (2014). Information technology and patient health: An expanded analysis of outcomes, populations, and mechanisms. Available at SSRN 2445431.

Gresenz, C. R., J. Rogowski, and J. J. Escarce (2007). Health care markets, the safety net, and utilization of care among the uninsured. Health services research 42(1p1), 239-264.

Hillestad, R., J. Bigelow, A. Bower, F. Girosi, R. Meili, R. Scoville, and R. Taylor (2005, 
Sep-Oct). Can electronic medical record systems transform health care? Potential health benefits, savings, and costs. Health Affairs 24(5), 1103-17.

Hing, E., C. Burt, and D. Woodwell (2007). Electronic medical record use by office-based physicians and their practices: United states, 2006. Advance Data from Vital and Health Statistics (393), 1-6.

Institute of Medicine (IOM) (2009). State of the USA Health Indicators: Letter Report. Washington, DC: The National Academies Press.

Jha, A. K., T. G. Ferris, K. Donelan, C. DesRoches, A. E. Shields, S. Rosenbaum, and D. Blumenthal (2006). How common are electronic health records in the united states? a summary of the evidence. Health Affairs 25(6), w496-w507.

Jiang, H. J., C. A. Russo, and M. L. Barrett (2009). Nationwide frequency and costs of potentially preventable hospitalizations, 2006. HCUP Statistical Brief 72, U.S. Agency for Healthcare Research and Quality, Rockville, MD.

Jones, S. S., J. L. Adams, E. C. Schneider, J. S. Ringel, and E. A. McGlynn (2010). Electronic health record adoption and quality improvement in us hospitals. American Journal of Managed Care 16(12), SP64-SP71.

Kaplan, B., P. F. Brennan, A. F. Dowling, C. P. Friedman, and V. Peel (2001). Toward an informatics research agenda: Key people and organizational issues. Journal of the American Medical Informatics Association 8(3), 235-241.

Kern, L. M., R. Dhopeshwarkar, Y. Barrón, A. Wilcox, H. Pincus, and R. Kaushal (2009). Measuring the effects of health information technology on quality of care: a novel set of proposed metrics for electronic quality reporting. Joint Commission Journal on Quality and Patient Safety 35(7), 359-369. 
Lee, J., Y.-F. Kuo, and J. S. Goodwin (2013). The effect of electronic medical record adoption on outcomes in us hospitals. BMC Health Services Research 13(1), 39.

Lin, Y.-K., M. Lin, and H. Chen (2014). Beyond adoption: Does meaningful use of ehr improve quality of care? Available at SSRN 2444054.

McCullough, J. S., S. Parente, and R. Town (2013, January). Health information technology and patient outcomes: The role of organizational and informational complementarities. Working Paper 18684, National Bureau of Economic Research.

Miller, A. R. and C. Tucker (2009). Privacy protection and technology diffusion: The case of electronic medical records. Management Science 55(7), 1077-1093.

Miller, A. R. and C. Tucker (2014a). Health information exchange, system size and information silos. Journal of Health Economics 33, 28-42.

Miller, A. R. and C. E. Tucker (2011). Can health care information technology save babies? Journal of Political Economy 119(2), 289-324.

Miller, A. R. and C. E. Tucker (2014b). Electronic discovery and the adoption of information technology. Journal of Law, Economics, and Organization 30(2), 217-243.

Office of the National Coordinator for Health Information Technology (2015, January). Federal health it strategic plan 2015-2020: Quick reference factsheet. World Wide Web.

Simon, S. R., R. Kaushal, P. D. Cleary, C. A. Jenter, L. A. Volk, E. J. Orav, E. Burdick, E. G. Poon, and D. W. Bates (2007). Physicians and electronic health records: a statewide survey. Archives of Internal Medicine 167(5), 507-512.

Spetz, J., J. F. Burgess, and C. S. Phibbs (2014). The effect of health information technology implementation in Veterans Health Administration hospitals on patient outcomes. Healthcare 2(1), 40-47. 
Tang, P. C. and C. Newcomb (1998). Informing patients: A guide for providing patient health information. Journal of the American Medical Informatics Association 5(6), 563-570.

US Department of Health and Human Services, Health Resources and Services Administration, Bureau of Health Workforce (2013-2014). Area Health Resources Files (AHRF). Rockville, MD. 


\section{Appendix Tables}

Table A-1: Representativeness of the Counties in the Merged Panel Database

\begin{tabular}{lccc} 
& & & \\
& Mean & Std. Dev. & Obs. \\
\hline In Sample & & & \\
Short-Term Hosp. Beds (Per 1,000) & 3.21 & 3.89 & 25030 \\
Primary Care Physicians (Per 10,000) & 6.91 & 4.38 & 25030 \\
FQHC Grantees (Per 100,000 Low-Income) & 14.0 & 34.3 & 25030 \\
Health Care Spending (000s USD) & 5100.9 & 5268.1 & 25030 \\
State HMO Penetration & 15.8 & 9.69 & 25030 \\
State Uninsured Percent & 14.5 & 4.15 & 25030 \\
Median Household Income (000s USD) & 42.5 & 10.9 & 25030 \\
County Poverty Percent & 14.5 & 5.42 & 25030 \\
\hline Missing EMR Data & & & \\
Short-Term Hosp. Beds (Per 1,000) & 2.46 & 4.69 & 5800 \\
Primary Care Physicians (Per 10,000) & 4.01 & 3.50 & 5800 \\
FQHC Grantees (Per 100,000 Low-Income) & 51.1 & 124.6 & 5800 \\
Health Care Spending (000s USD) & 4779.6 & 4460.5 & 5800 \\
State HMO Penetration & 13.5 & 8.09 & 5800 \\
State Uninsured Percent & 16.2 & 4.40 & 5800 \\
Median Household Income (000s USD) & 37.3 & 9.26 & 5800 \\
County Poverty Percent & 17.2 & 7.07 & 5800 \\
\hline Observations & 30830 & & \\
\hline \hline
\end{tabular}

County-year unit of observation. 
Table A-2: Summary Statistics for PQI Rates by Age Group

\begin{tabular}{lccccc}
\hline \hline & & & & & \\
& Mean & Std. Dev. & Min. & Max. & Obs. \\
\hline Overall PQI Rate & 1280.3 & 1154.7 & 0 & 9563.6 & 4725 \\
18 to 39 & 243.0 & 252.4 & 0 & 3670.4 & 4686 \\
40 to 64 & 794.6 & 819.8 & 0 & 9582.9 & 4716 \\
65 to 74 & 2494.8 & 2243.8 & 0 & 17059.6 & 4394 \\
75 Plus & 5766.3 & 4481.2 & 0 & 30769.2 & 4383 \\
PDI Rate (NIS) & 117.3 & 182.0 & 0 & 4060.0 & 4622 \\
PDI Rate (KID) & 156.3 & 165.9 & 0 & 2198.7 & 1535 \\
\hline \hline
\end{tabular}

County-year unit of observation. The PQI rate is for adults age 18 and older per 100,000 population. The PDI rate measures preventable admissions per 100,000 population for children ages 6 to 17. PQIs are calculated using NIS. PDIs are calculated separately using NIS and KID data. 